\title{
DP-834
}

RETIEASED FOR ANDOUNCTMNT

IN NUCIEAR SCIFACE ABSTRACTS

AEC RESEARCH AND DEVELOPMENT REPORT

\section{DEVELOPMENT OF A TEMPERATURE MONITOR FOR LARGE REACTORS}
A. H. DEXTER M. H. GOOSEY
C. R. HUTtER R. W. LEEP

J. N. WILSON

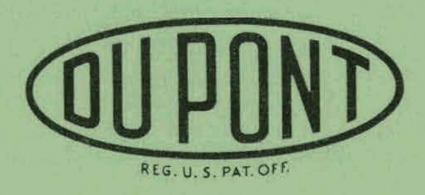

Savannah River Laboratory

Aiken, South Carolina 


\section{DISCLAIMER}

This report was prepared as an account of work sponsored by an agency of the United States Government. Neither the United States Government nor any agency Thereof, nor any of their employees, makes any warranty, express or implied, or assumes any legal liability or responsibility for the accuracy, completeness, or usefulness of any information, apparatus, product, or process disclosed, or represents that its use would not infringe privately owned rights. Reference herein to any specific commercial product, process, or service by trade name, trademark, manufacturer, or otherwise does not necessarily constitute or imply its endorsement, recommendation, or favoring by the United States Government or any agency thereof. The views and opinions of authors expressed herein do not necessarily state or reflect those of the United States Government or any agency thereof. 


\section{DISCLAIMER}

Portions of this document may be illegible in electronic image products. Images are produced from the best available original document. 


\section{LEGAL NOTICE}

This report was prepared $a s$ an account of Government sponsored work. Neither the United States, nor the Commission, nor any person acting on behalf of the Commission:

A. Makes any warranty or representation, expressed or implied, with respect to the accuracy, completeness, or usefulness of the information contained in this report, or that the use of any information, apparatus, method, or process disclosed in this report may not infringe privately owned rights; or

B. Aooumeo any liabilition with roopoet to the uoe of, or for damagco reoulting from the use of any information, apparatus, method, or process disclosed in this report.

As used in the above, "person acting on behalf of the Commission" includes any employee or contractor of the Commission, or employee of such contractor, to the extent that such employee or contractor of the Commission, or employee of such contractor prepares, disseminates, or provides access to, any information pursuant to his employment or contract with the Commission, or his employment with such contractor.

Printed in USA. Price $\$ 1.00$

Avallable from the Clearinghouse for Federal Scientific and Technical Information, National Bureau of Standards,

U. S. Department of Commerce, Springfield, Virginia 
$\mathrm{DP}-834$

Instruments

(TID-4500)

CFSTI PRICES
H.C. $\$ 1.00 ; M N \quad$.50

DEVELOPMENT OF A TEMPERATURE MONITOR FOR LARGE REACTORS

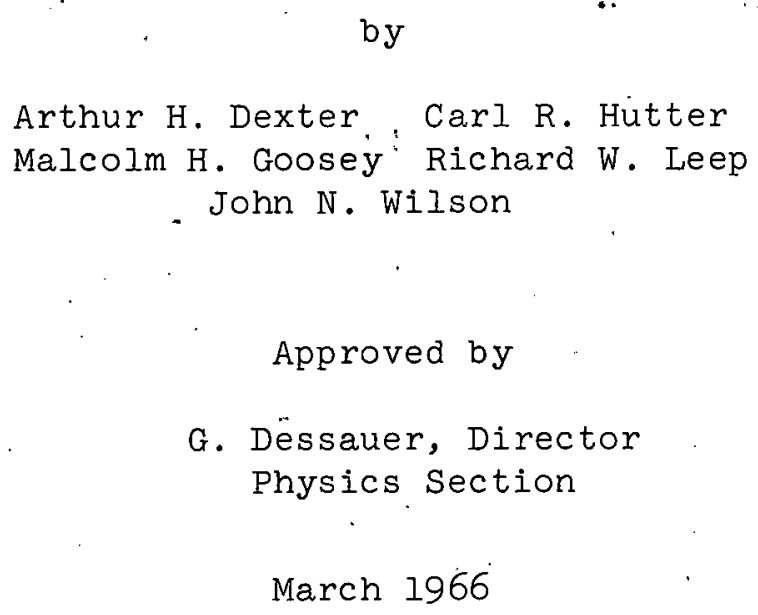




\section{ABSTRACT}

A tcmperature monitor was designed to measure the temperature rise of coolant flowing through each fuel channel of a nuclear reactor. Although the monitor was intended for use with a large. heavy water-cooled reactor, the design principles are. generally applicable to large. power and production reactors that employ forced flow of coolant.

A scanning monitor was chosen because it has more economic and operational advantages than a continuous monitor. Digital circuitry permits. automatic programming, arithmetic. operations, and visual displays. Arguments are presented for types. of alarms which should be provided. 


\section{CONTENTS}

$\underline{\text { Page }}$

Introduction $\quad$. 4

Summary : : 4

Discussion 5

Instrument Considerations $\quad . \quad 5$

Temperature Sensors .. . . . . 5

Junction Compensation. . . . . . . . 6

Monitor Type (Scanning vs. Continuous Monitoring) 6

Data Utilization . . . .8

Alarms . 8

Operational Displays $\quad \because \quad 10$

Detecting and Locating Falled Fuel Elements 13

Computations . . . . . 14

Data Readouts $\quad 15$

Data Loggers 15

Conceptual Design for a Temperature Monitor 15

BIbllography 18

\section{LIST OF FIGURES}

\section{Figure}

IA Continuous Type Monitor 7

IB Scanning Type Monitor $\quad \cdots$

2 System Cost vs. No. of Inputs 8

3 Considerations in Establishment of Second : Il
Alarm Level

4 Conceptual Des1gn for a Temperature Monitor 16 


\section{DEVELOPMENT OF A TEMPERATURE MONITOR FOR LARGE REACTORS}

\section{INTRODUCTION}

Temperature monitoring of the fuel coolant is an essential feature of almost all designs for high power reactors. However, the complexity of the monitoring system and the extent to which the safety and efflciency of the reactor are made to depend upon this system can vary greatly between different designs. During the past several years, the authors have been involved in the design of an advanced type of monitor for the coolant temperatures in a large heavy-water-cooled reactor. Th1s report gives the design phllosophy which was evolved in the course of this project. It is belleved that these ideas have applications considerably beyond the immediate reactor type for whlch they have been developed.

\section{SUMMARY}

The basic philosophy behind the temperature monitor design was that the detalled measurement of fuel coolant temperatures provides an accurate, reliable, and reasonably avallable diagnostic tool for determining the reactor performance. Specif1cally, this data can be used to indlcate unsafe reactor operation, to provide a bas1s: for detalled reactor control, and to warn of fuel element fallures. The safety requirements. necessitate extensive and rapld sampling of the full range of coolant temperatures while the control requirements invite the use of digital clrcuitry and visual display to put the temperature: data into a useful f'orm.

A major design decision for the temperature monitor involves the cholce between a scanning monitor covering many temperature sensors or a continuous system for each sensor. The scanning systems were judged superior for any large reactor. Fast acting switches are now avallable which permit the scanning of the temperature sensors at speeds that are in general greater than the response time of the sensor. These sequential data are then in the ideal form for operation of the digital circuits. Discussions of the various alarm requirements are given as well as methods for their implementation in both the digital-circuitry design and the read-out devices. The discussion is carried to the point of presenting a conceptual design of a monitor which meets the requirements developed in this report. 


\section{DISCUSSION}

Fuel elements must be operated at high temperatures for economical operation of power and production reactors, and the margin between the operating temperature and the limiting safe temperature is usually very small. The flow of coolant through a fuel element may be partially blocked by a swollen fuel element or accidental intrusion of a forelgn object. Such a restriction of flow may cause the fuel element to melt.

Accidents of this type can be avolded by monitoring the temperature of the fuel elements with sufficient precision. This could be accomplished by means of temperature sensors located on or in the fuel elements, but this method cannot be employed, particularly with water-cooled reactors, because of the risk of impairing the integrity of the fuel elements and the connect-disconnect problems during the charging and discharging operations. Therefore, the fuel temperatures are monitored indirectly by measuring the temperature increase of the coolant with sensors at the inlet and outlet ends of each coolant channel. Since fuel elements usually have a commori coolant inlet, only a few inlet temperature sensors are required. The temperature increase $(\Delta \mathrm{T})$ across the fuel element is then an indirect measure of the fuel element temperature, provided the coolant flow 1 s constant and the shape of the axial neutron flux is known. These provisions usually apply in the case of large reactors; because constant flow is maintained and the axial flux is monitored with either activated wire or internal flux monitors(1).

\section{INSTRUMENT CONSIDERATIONS}

General reactor considerations usually determine the form and specific features of a temperature monitor. These considerations should be apparent, but have not been discussed previously in the ilterature.

\section{Temperature Sensore}

The designer must choose either thermocouples or resistance thermometers. For optimum sensitivity the exit coolant sensors should be located as close as possible to the end of the fuel channel. This of course implies that the sensor will be subjected to radiation from within the reactor. Experience indicates that only thermocouples can survive. this environment for extended periods. Resistance thermometers can be used, however, in lesser radiation fields. Mineral-insulated thermocouples of both chromel-alumel and Iron-constantan materials, enclosed in stainless steel sheaths, have been used successfully for the temperature range of 100 to $600^{\circ} \mathrm{C}$. The output of these the rmocouples is about $50 \mu \mathrm{V} /{ }^{\circ} \mathrm{C}$. 
The response time of the thermocouple (and the associated monitoring equipment and trip circults) should be short compared with the time in which a fuel element would melt as the result of a temperature transient. Fuels consisting of enrlched alloys of uranium and other metals, for example, can melt in a relatively short time due to their small heat capacity, whereas melting would require allonger period with solid uranium or oxide-type fuel elements, which have an inherently greater heat capacity. If a very short time response is required, the thermocouple junction should be grounded to the enclosing sheath. Response times of about 0.1 second can be achieved in this manner.

\section{Junction Compensation}

Cold function errors can be handled in a number of ways $^{(2)}$; however, in the case of a temperature monitor in whish hundreds or thousands of thermocouples must be dealt with, it is more economical to employ a single common compensating unit for all thermocouples. It is commori practice to join the thermocouple leads to pairs of copper wire that $c$ an be routed some distance to the temperature monitor, which is usually located in a radiation-free region such as a control room. One method of compensating for the cold junction error is to enclose the junctions in a large, temperature-controlled oven, but this method requires fairly elaborate thermostating and associated control systems and $a$ large oven requiring considerable power. Most of these difficulties can be overcome with a scanning-type system that employs multi-input switches to sequentially route a large number of thermocouple signals into a common output channel. The scanning syctem permits the use of a common compensating oven:

The preferred compensation system employs an 1sothermal box to maintain all junctions. at the same (but not constant) temperature. This arrangement permits temperature variations to be compensated by one unit. The isothermal box is relatively $31 \mathrm{mple}$ and eliminates the numerous problems associated with the thermostated oven.

\section{Monttor Type (Scanning vs. Continuous Monitoring)}

The small DC output voltages of the thermocouples must be amplified before they $c$ an be used. Since a large reactor of the type under discussion will normally use 200 to 2000 thermocouples, a considerable quantity of electronic equipment will be' required. The monitor can take one of two basic forms: it may be a continuous system that uses a separate amplifier plus assoclated equipment for each thermocouple to be monitored, 
or it may be a scanning system that uses multi-input switches to sequentially route a number of thermocouple voltages through. a single amplifier and associated circuitry. The difference between these two systems is shown schematically in Figure 1 for a rudimentary temperature monitor that provides an alarm if any thermocouple voltage exceeds a fixed alarm setting.

The continuous system provides data continuously. The same protection can be provided by the scanning system if the multi-input switch is fast enough that each thermocouple voltage is measured in less time than the response time of the thermocouples. For example, if the response time of the thermocouples was 1 second and each thermocouple was read 10 times per second, the scanning monitor would provide essentially continuous process protection.

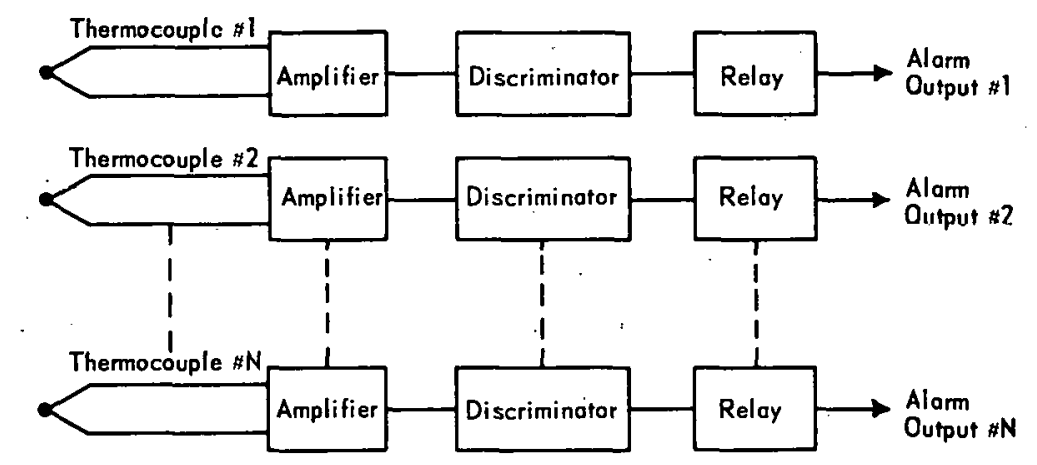

FIG. IA CONTINUOUS TYPE MONITOR

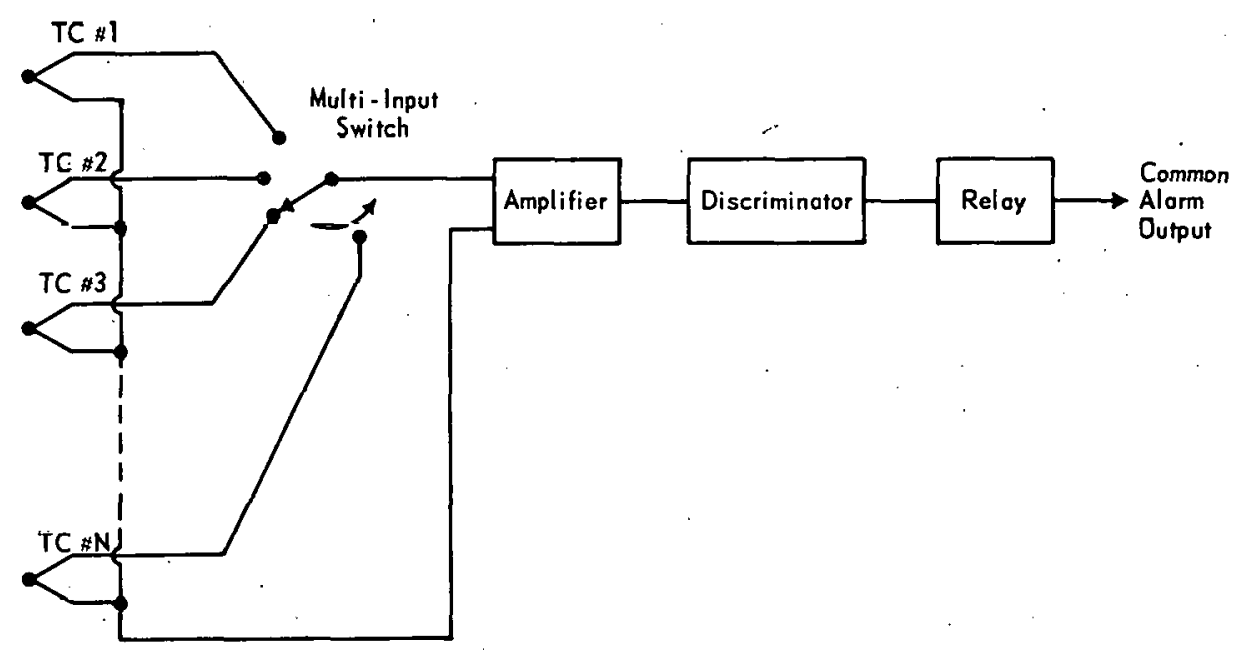

FIG. I.B SCANNING TYPE MONITOR 
Continuity of operation is thus not a consideration in selecting between the two systems if multi-input switches with sufficlent speed are avallable. Perhaps the most important difference between the two rudimentary systems of Figure 1 is the matter of economics. If, for example, a multi-input switch with $\mathrm{n}$ inputs $\mathrm{can}$ be obtained for less than the cost of the $(n-1)$ amplifiers and discriminators that 1 t replaces (other things being equal), then the scanning system is preferable to the continuous system. In practice, it is usually found that for a small number of inputs the continuous system is more economical, but for a large number of inputs', as in the case of a large reactor, the scanning system is more economical. The general relationship between the cost and the number of monitored inputs is shown in Figure 2 .

Other considerations that tend to favor the use of a scanning monitor are shown in the following section.

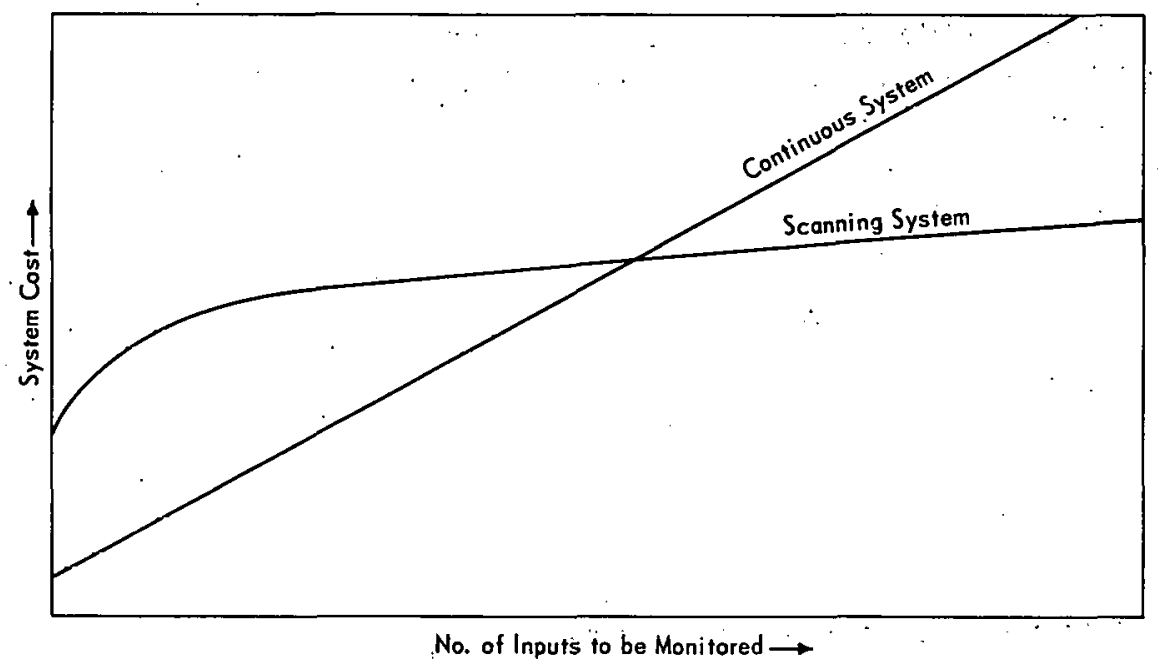

FIG. 2 SYSTEM COST VS. NO. OF INPUTS

\section{DATA UTILIZATION}

Only a rudimentary system that provides limited process protection has been considered. In practice; a temperature monitor may be called upon to provide much more protection and information for control purposes.

\section{$\underline{\text { Alarms }}$}

As previously noted, certain condltions lead to temperature increases; in certain circumstances the rise may be rapid enough that the operator does not have sufficient time to manually prevent damage to the reactor. For the protection 
of the reactor, several types of alarms should be provided. of primary importance is an alarm that will be actuated if the temperature of the coolant approaches some limiting value.

This limiting value might be the temperature at which bulk bolling of coolant occurs in a liquid-cooled fuel element: Since this limiting value is a flxed temperature, the temperature monitor should provide. one set of output signals that are proportional to the absolute outlet temperature of the coolant. Since the reactor will almost certainly be damaged if this temperature is exceeded, this output alarm should be connected to the automatic shutdown circuits that insert the safety rods.

A second alarm is desirable at a lower temperature level to permit the initiation of lesser corrective action such as the slow insertion of the control rods to reduce the reactor power to a safe level. It would be possible to use the absolute temperature signal previously cited and to have the assoclated circultry arranged to provide an alarm if any temperature exceeded a certain fixed value that was less than the limiting temperature (e.g., the alarm level might be set $5^{\circ} \mathrm{C}$ less than the limlting temperature alarm level). Unfortunately, this arrangement does not provide for the earliest recognition of a rising temperature for all fuel positions in the reactor. If, for example, the radial temperature profile across the reactor is as shown in Figure $3 a$ and the second alarm level is set a constant amount below the limiting temperature alarm level, the temperature of a fuel channel in the outer reglons of the reactor would have to rise a considerable amount, as contrasted with one near the center, before 1t actuated the second level alarm.

It would be preferable for the temperature monitor to provide an alarm level that parallels the reactor temperature profile as shown in Figure $3 \mathrm{~b}$; this level could be $5^{\circ} \mathrm{C}$ greater than the temperature of any channel in a "normal" reactor temperature profile.

In the case of the continuous system, the voltage difference between each thermocouple signal and an individually adjustable reference voltage is fed to a discriminator. In the case of the scanning system, a second bank of switches, phased with the input bank, connects each thermocouple signal with its respective adjustable reference voltage. The difference voltages are fed to a common discriminator.

Both of these systems share the same significant deficiency, namely, the need for manual adjustment of the 200 to 2000 reference potentiometers. If the monitor is to provide the desired second level protection and not generate false alarms, it is necessary to readjust all of the 
reference voltage potentiometers several times during a power ascension and periodically after full power 1s attained, due to the changes in the radial temperature profile that occur during a fuel cycle. These adjustments may require as much as an hour, during which time the monitor must be disconnected from the automatic control rod insertion circuits to avoid false insertions.

The loss of the protection of the temperature monitor during these periods is undesirable and a method is needed for rapidly and automatically adjusting the reference voltages or for performing the equivalent function. It is not obvious how such a scheme could be applied to the continuous system other than by means of a very complex electro-mechanical servo system. The scanning monitor, however, lends 1 tself quite readily to automatic adjustment (1.e., programming). It is possible, for example, to sequentially record all of the amplified thermocouple vultageo on magnetis tape a.t some instant when the reactor temperature profile is considered to be normal. This can be accomplished in a relatively short time. The recorded temperatures can then be sequentially "read" off of the tape by conventional techniques, and compared with current temperatures at a later time. If any voltage difference exceeds a fixed discriminator setting, an alarm is generated as before. Those who are familiar with modern digital data handling systems will recognize that the magnetic tape scheme can be performed even more rapidly with memory devices of the type exemplified by the magnetic drum ${ }^{(3)}$ or the core-store matrix $(4)$ to provide even fas.ter programming and comparison. The adaptability of the scanning system to automatic programming is thus another of the important advantages of scanning systems over continuous systems.

A third alarm level should be included for taking corrective manual action "when the temperature rise is slow enough to permit such action. Trils alarm need only actuate an annunclator and/or light to call attention to the abnormal condition. A convenient way of providing this alarm is to route the signal employed for the second-level alarm to a discriminator that is set to actuate the annunclator if any coolant channel temperature increases a small amount $\left(2^{\circ} \mathrm{C}\right)$ above normal.

\section{Operational Displays}

The temperature monitor is important in reactor operation. The coolant temperatures can be used to optimize the radial temperature profile of the reactor by adjustment of the various control rods. In large reactors, in which the central zone temperatures can be flattened, the number of fuel elements operated at maximum temperature can be maximized. 

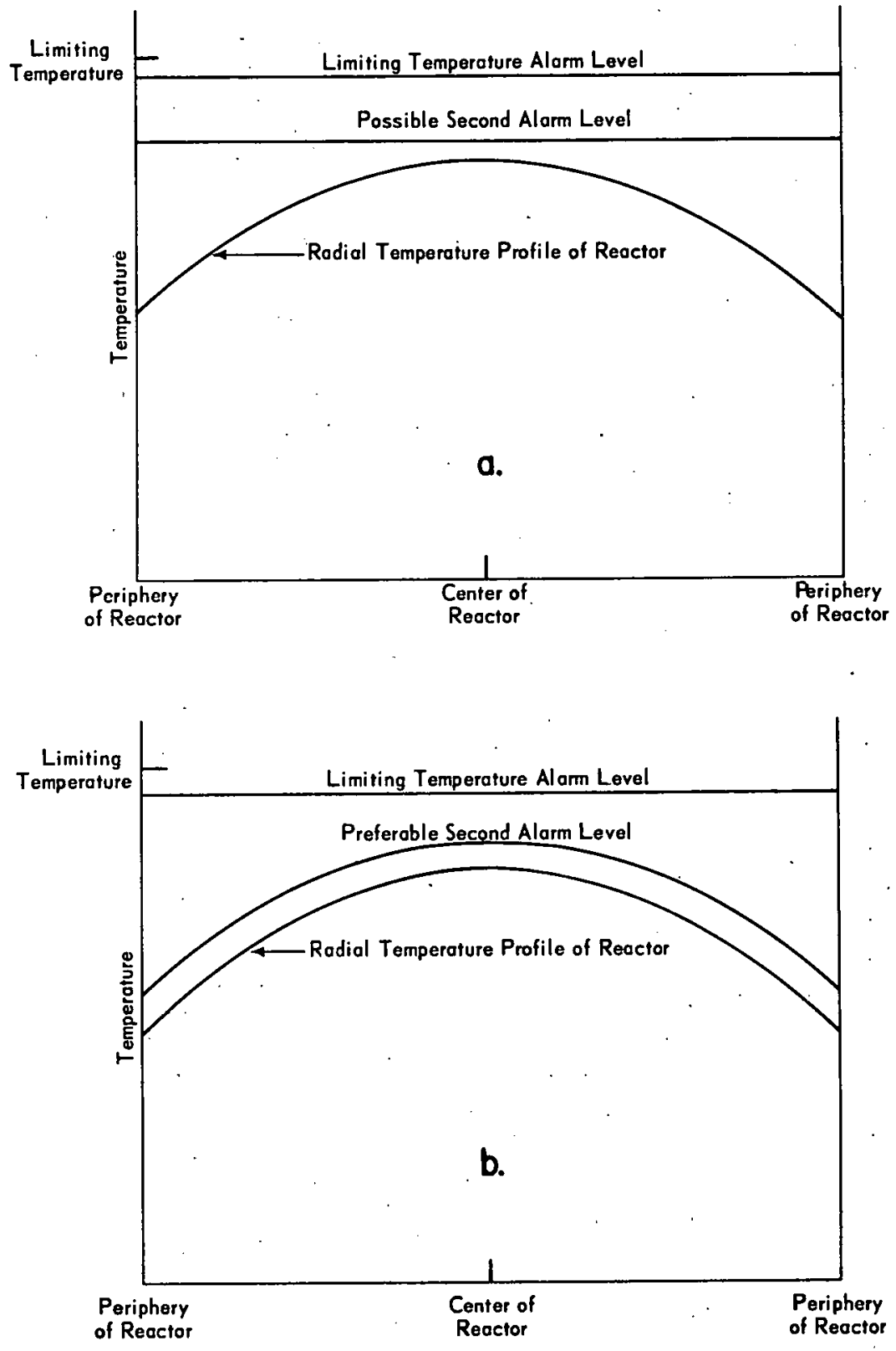

FIG. 3 CONSIDERATIONS IN ESTABLISHMENT OF SECOND ALARM.LEVEL 
A visual display is the most efficlent way of presenting this temperature information to the operator; a display that shows the coordinates (address) of each fuel element and provides a visual (not numerical) indication of temperature is probably the most useful. Although actual three-dimensional displays are difficult to construct, two-dimensional displays of varlous types can be constructed that are adequate to meet operating needs. (By analogy, a topographical map is just about as useful as a three-dimensional model.). .

A visual display may be generated by the monitor, or the monitor may merely supply temperature data from which a display can be generated manually. The latter method was employed at an early date and is still in use. The manual method involves determination of the temporature rise ( $\Delta \mathrm{T})$ of eash fuel channel, which can be done by connecting a millivoltmeter, in turn, to each of the process thermocouples and an inlet reference thermocouple so as to obtain the $\Delta T$ !s. The temperatures are transcribed to a coordinate map of the reactor and each coordinate is colored-in by hand to indicate the incremental range of temperature. Red can be used to indicate the hottest increment, orange the next, and so on through the spectrum. This results in a simple visual display, but contains some deficiencies. It is tedious and time consuming and does not allow the operator to see immediately the consequences of moving the control rods. Electronic techniques now avallable make it unlikely that the manual method will recelve any serlous consideration in the future.

The automatically generated visual display can take a number of forms. A color television presentation is certainly feasible and can provide the equivalent of the manualiy generated display. However, no such dioplay has been bu11t. A black and white television presentation, where the various shades of gray correspond to temperature increments, is equally fcasible and somewhat easier to accomplish(5). Electroluminescent screens with larger displays offer future promise.

All of these displays have (in theory at least) the potentiality of displaying simultaneously the incremental temperature of each fuel channel, but none can present more than a limited number of temperature increments. The black and white television presentation, for example, is limited by the number of shades of gray the eye can distinguish (1.e., about 7 shades). Another type of display - the bulb panel display - offers an unlimited number of increments, but only one increment $c$ an be viewed at a time.

The bulb panel has small electric lights disposed in a two-dimensional array so that each bulb represents a particular 
fuel channel coordinate. Sultable discriminators switch the bulbs "on" or "off" depending upon the temperature of the fuel channels. The discriminators may be varied over wide limits to examine the temperature profile of the reactor in detail, but not all of the fuel channels can be viewed simultaneously.

The displays mentioned are not all-inclusive, but are Indicative (with the exception perhaps of the electroluminescent screen) of what can be accomplished automatically today. These readouts are only practical with scanning monitors-a result of the sequential train of signals avallable from a scanning monitor. These signals can then be passed through the same common discriminator(s) in order to modulate the intensity of the electron beam of the television tube or to light or extinguish bulbo.

The panel can also show whlch fuel channel produced an al arm.

\section{Detecting and Locating Falled Fuel Elements}

In some multichannel reactors, temperature monitors can detect and locate falled fuel elements if the reactor has: (1) relatively small coolant channels, (2) a sufficlently large temperature increase across the fuel channel, and (3) fuel elements that swell when coolant interacts with fuel. Under these conditions, the inftial swelling of the fuel element is often sufficient to impede coolant flow slightly and to produce a small increase in coolant temperature. A common discriminator usually cannot be set at some alarm level to detect these inftially small temperature increases because they are of the same magnitude as normal variations. It would be unsafe to walt until the swelling of the fuel element is sufficient to exceed an alarm level that is significantly in excess of the background variations.

At least two methods are recognized for handling this special problem. The first uses conventional recording of temperature vs. t1me, coupled with the ab1l1ty of the human eye to percelve small but signiflcant changes in temperature in one of many slowly undulating recordings. One such system, which employs segmental recorder's, has been used successfully at this site for a number of years. The segmental, recorder is unique in that it permits the intermittent recording of signals from more than 500 thermocouples for 24 hours without replacement of the chart paper(6). The obvious disadvantage of the recording method is the need for continual surveillance. 
Automatic detection of fuel failures offers considerable promise, but to date 1 t has been evaluated only to a limited extent by calculation. This method assumes that the temperature difference between the $\Delta T$ of a glven fuel channel and the average of all other fuel channel $\Delta T^{\prime} s$ in the same fuel element will be essentially constant, under normal conditions, during the fuel cycle. If one takes the indicated temperature difference at some time zero (e.g., after the first attainment of power) and then compares subsequent values during the fuel cycle with the initial value by taking a second difference, then the second difference should remain essentially constant (or at worst vary within certain small limits). If, however, a fuel fallure occurs and the fuel swells, thereby constricting and increasing the $\Delta \mathrm{T}$ of the channel, the second difference will tend to change. in value and will inorease markedly. This method has been applied, in hand-calculated form, to long-term temperature data from fuel elements that subsequently falled, and from all lidication the method is applicable. The results indicate that this system should make it possible to detect fuel failures as soon as they are now detected with activity monitors. An example of the method, for a fuel element with four flow channels, is given in a classified version of this report (DP-810). An alarm can be obtained automatically. from the monitor if certain. simple computational and memory features which perform the indicated hand calculations by electronic means are incorporated. Such features can be provided easily if the monitor is of the scanning type and employs digital data-handling circultry. (1.e., if the analog voltage signals from the thermocouples are digitized with an analog-to-digital converter and subsequently handled in the digitized form).

The location (address) of the falled fuel element can be sultably displayed w1th additional c1rcultry.

\section{Computations}

The operation of a reactor often requires perlodic hand computation of certain values such as hydraulic limits and burnout safety factors. Since many of these computations involve temperature data already available in the monitor, plus some small amount of data from other sources, it is not unreasonable to incorporate the necessary computational ability within the monitor. This faclity can probably be added to the monitor for only a slight additional expense in the case of a scanning monitor that employs digital circultry. 


\section{Data Readouts}

It is often desirable to monitor the temperature of a given fuel channel for some short period of time or on a continuous basis. This can be done simply by providing jacks on each thermocouple pair to permit connection of a millivoltmeter or recorder, or it $c$ an be done more elaborately by presenting a ${ }^{\circ} \mathrm{C}$ reading on "Nixie"-type bulbs in response to punching in of the address of the desired thermocouple.

\section{Data Loggers}

It should not be necessary to continuously record all of the reactor temperatures. The data obtained from recorders or printers are in a furm that cannot be conveniently utilized. It should be possible to present worthwhile data in the form that can lead to the required operator action, as discussed previously. However, the designer cannot foresee all future eventualities, and it may be desirable to obtain logs of the temperature data under altered conditions. A visual readout of individual temperatures could be used to provide these data, but the data would not necessarily be time-concurrent. Therefore, plug-in provisions should be made for the later addition of an automatic printer(7), even though the printer is not included in the original equipment.

\section{CONCEPTUAL DESIGN FOR A TEMPERATURE MONITOR}

A general-purpose temperature monitor can be designed on the basis of the previous discussions and conclusions (see Figure 4). For the reasons previously stated, the monitor is of the scanning type. Digital circuitry is employed for convenience in the storage of data and the performance of computations. This conceptual design can be modified to oult most reaclor temperature monitoring requirements .

The inlet and outlet thermocouples are terminated at an isothermal panel located near the reactor. These signals, plus the signal from a thermocouple that measures the isothcrmal panel temperature, are brought out on long copper pairs that lead to the temperature monitor (located in or near the control room of the reactor) and are terminated at the input to the scanning.switches. The signals at the input to the scanning switches are:

(1) Coolant outlet signals $\left(t_{1}-t_{1 \text { so }}\right),\left(t_{2}-t_{150}\right),\left(t_{1}-t_{150}\right)$

(2) Coolant inlet signal $\left(t_{r}-t_{1 s o}\right)$

(3) Reference signal $\left(t_{1 \text { so }}-r\right)$

where $r$ is an internally generated reference signal. 


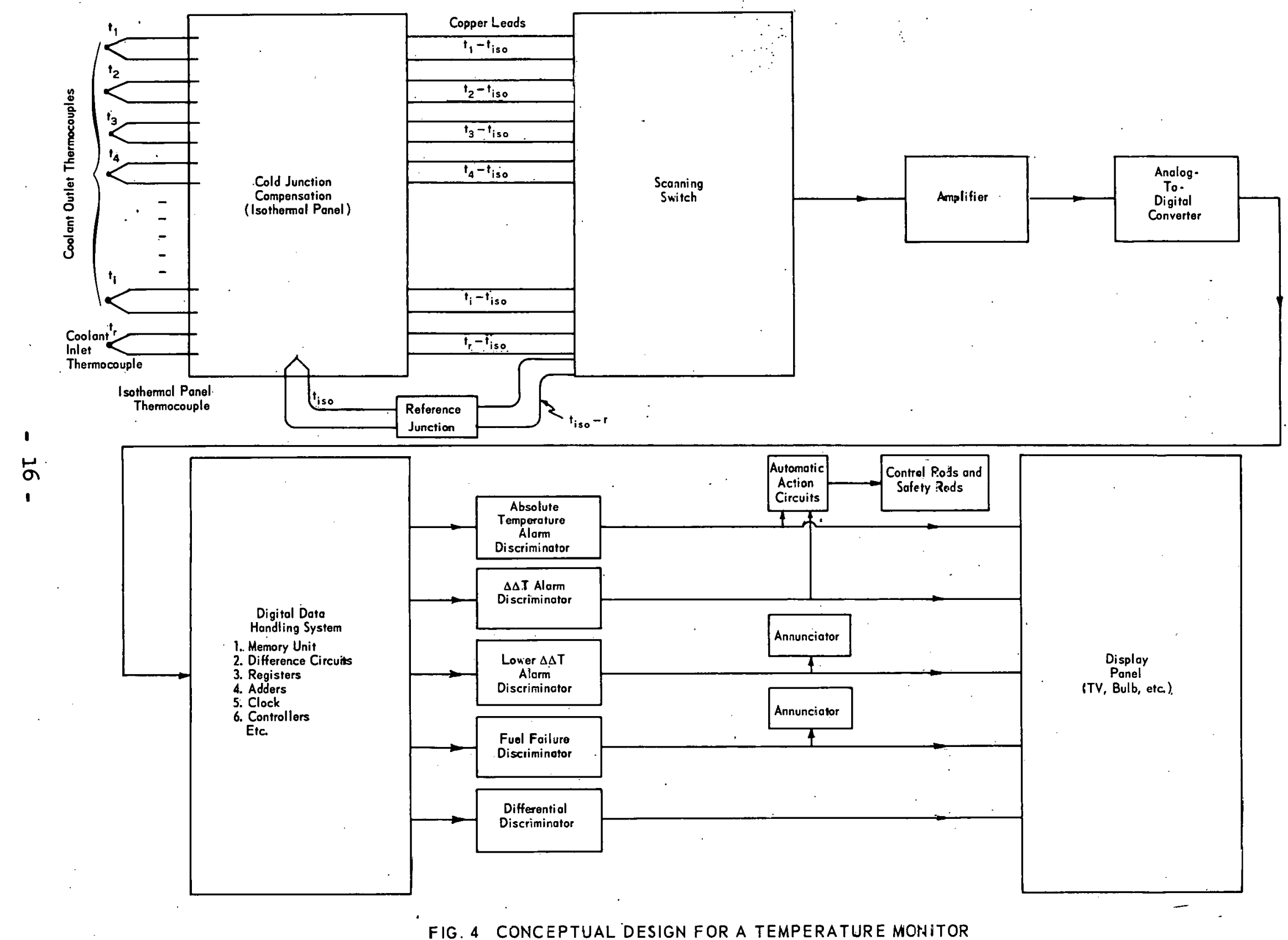


The type of switch depends upon the rapidity with which temperature transients or accidents can occur within the reactor. Stepping switches could be employed for times of the order of minutes and elther fast relays or transistor switches for times of the order of 0.1 second.

After suitable amplification, the thermocouple signals are converted to digital form with an analog-to-digital converter, giving the digitized signals $\left(\mathrm{T}_{1}-\mathrm{T}_{1 \mathrm{so}}\right),\left(\mathrm{T}_{\mathrm{R}}-\mathrm{T}_{\text {1so }}\right)$, and $\left(\mathrm{T}_{1 \mathrm{so}}-\mathrm{R}\right)$.

Within the digital system, the absolute temperature is obtained by subtracting $\left(\mathrm{T}_{1 \mathrm{so}}-\mathrm{R}\right)$ from each of the $\left(\mathrm{T}_{1}-\mathrm{T}_{1 \mathrm{so}}\right)$ values to yield $\left(T_{1}-R\right)$; $1 . e$. , the absolute temperature minus a constant. These values are then fed to an alarm discriminator, which institutes automatic action if any value exceeds the absolute temperature discriminator setting, and to the display panel, which permits the coordinates (address) of any alarm to be determined.

In similar fashion the $\Delta T$ across each fuel element is determined by subtracting $\left(T_{R}-T_{150}\right)$ from each $\left(T_{1}-T_{1 s o}\right)$ to yield $\left(\mathrm{T}_{1}-\mathrm{T}_{\mathrm{r}}\right)$ or $\Delta \mathrm{T}_{1}$. The initial $\Delta \mathrm{T}_{1}$ values, 1.e., $\Delta \mathrm{T}_{10}$ are stored in the memory unit when the reactor reaches full power, and are read off each cycle of the scanner for comparison with the current $\Delta \mathrm{T}_{1}$ values. If the difference $\left(\Delta \mathrm{T}_{1}-\Delta \mathrm{T}_{10}\right)$ or $\Delta \Delta \mathrm{T}_{1}$ exceeds the temperature rise discriminator setting, an alarm is generated. An approach discriminator, set at a lower level, provides an annunciator indication that alerts the operator and permits him to take corrective manual action.

The fuel fallure feature operates from either the $\left(T_{1}-R\right)$ or the $\Delta T_{1}$ values. As an example, the $\left(T_{1}-R\right)$ values for all of the channels of a fuel element $c$ an be summed and divided by the number of fuel channels to give $\left(T_{1}-R\right)$ avg for that fuel element. This value is then subtracted from each of the channel $\left(T_{1}-R\right)$ 's to give a difference denoted as $D_{j k}$, where $j=$ the particular fuel channel number of fuel element number $k$. The initial values $D_{j k}(0)$ are stored at the attainment of full power and are compared with current values $D_{j k}(t)$ to give the sec ond difference $\Delta D_{j k}$. If any $\Delta D_{j k}$ value exceeds the fuel fallure discriminator setting, the operator is alerted by an annunclator.

The visual display for flattening and optimizing the radial flux of the reactor can be generated by passing the $\Delta \mathrm{T}_{1}$ values to sultable discriminators, differential or otherwise, to el.ther light bulbs or modulate the beam intensity of a TV tube. 
other features, such as the decimal readout of a particular fuel channel temperature can also be conveniently provided. The digital data $c$ an be utilized in a computer section if such requirements exist.

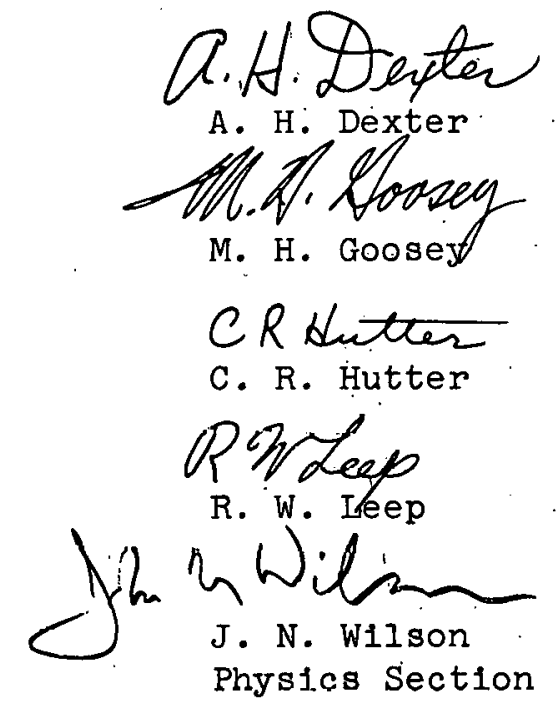

\section{BIBLIOGRAPHY}

1. Lapsley, A. C. "Neutron Gamma Measurements for In-P1le Power Mon1toring". Nucleonics 16, No. 2, 106-10 (1958); Loosemore, W. K. and J. A. DenniB. "The Continuous Measurement of Thermal-Neutron Flux Intensity in HighPower Nuclear Reactors". The Inst. of Electrical Engineers 108, Part B (1961); Preston, R. J. The MTR Automatic W1re Scanner. Phillips Petroleum Co., Idaho Falls, Idaho. AEC Research and Development Report IDO-16243, 44 pp. (1955).

2. Jones, E. B. Instrument Technology. Vol. 1. London: Butterworths Scientific Publications, p. 240 (1953).

3. Nelson, R. C. "Magnet1c Drums and D1scs". Instruments \&c Control Systems 35, 109-20 (1962); Williams, S. B. D1g1tal Computing Systems. New York: McGraw-H11l, p. 97 (1959).

4. Williams, S. B. Digital Computing Systems. New York: MeGraw-H1Il, p. 100 (1959); Whitmer, M. "Magnetic Memory Cores". Instruments \& Control Systems 34, 1427-29, (1961).

5. Lennox, C. G. and A. Pearson. "Versatile Data Displays for Reactors". Nucleonics 18 , No. 10, 82 (1960).

6. Dell, C. G. and L. P. Haner. "Segmental Recorders". J. Inst. Soc. of Amer. 1, No. 1, 27-39 (1954).

7. "Digital Printers". Instruments \& Control Systems 32, 700-07 (1959). 